\title{
Resistance to Tan Spot and Insensitivity to Ptr ToxA in Wheat
}

\author{
Angelo Jay Noriel, Xiaochun Sun, Willium Bockus, and Guihua Bai*
}

\begin{abstract}
Tan spot, caused by the fungus Pyrenophora tritici-repentis, is an important foliar disease of wheat (Triticum aestivum L.) worldwide. Growing resistant cultivars is an effective approach to reduce the losses caused by the disease. To identify resistance genes in common wheat, 380 wheat accessions from different geographical origins were evaluated for resistance to $P$. tritici-repentis race 1 , the predominant race in the Great Plains of the United States and western Canada, and insensitivity to Ptr ToxA, a host-selective toxin produced by race 1 . Most accessions tested (60\%) were resistant and only 93 accessions (24\%) were as susceptible as TAM 105, the susceptible control. Among 379 accessions, 230 were insensitive to Ptr ToxA, but only 158 of them showed resistance to race 1. A weak correlation between tan spot score and sensitivity to Ptr ToxA suggests that pathogenicity factors other than Ptr ToxA (like Ptr ToxC) also contributed to tan spot development in these accessions. The accessions with resistance to tan spot identified in this study should be useful sources for developing new tan spot resistant cultivars.
\end{abstract}

A.J. Noriel, X. Sun, and G. Bai, Dep. of Agronomy, Kansas State University, Manhattan, KS 66506; W. Bockus, Dep. of Plant Pathology, Kansas State University, Manhattan, KS 66506; G. Bai, USDA-ARSHard Winter Wheat Genetics Research Unit, Manhattan, KS 66506. Received 9 Aug. 2010. `Corresponding author (guihua.bai@ars.usda. gov, gbai@ksu.edu).

Abbreviations: \%LAD, percent leaf area diseased; HRW, hard red winter wheat; HST, host-selective toxin; SRW, soft red winter wheat.

$\mathrm{T}$ An Spot, caused by Pyrenophora tritici-repentis (Died.) Drechs, has become a global concern due to its detrimental impact on wheat (Triticum aestivum L.) production. The disease can cause yield losses up to $50 \%$ in some wheat fields, especially where highly susceptible varieties are planted (Riede et al., 1996) and reduced tillage is a common practice (Xu et al., 2004). Tan spot was reported as the most prevalent disease of wheat in Canada (Tekauz et al., 2004) and yield losses in Australia were reported from 13 to 48\% (Rees and Platz, 1983; Murray and Brenan, 2009). It is becoming more severe in the southern cone of South America, including Argentina, Brazil, Chile, Paraguay, and Uruguay (Perello et al., 2003). One of the most effective strategies for controlling tan spot is to grow resistant cultivars (Chu et al., 2008a). However, the majority of commercial wheat cultivars currently grown are still susceptible to tan spot (Lamari et al., 2005).

Eight races have been described for $P$. tritici-repentis (Lamari et al., 2003). Race 1 is the most prevalent race in the Great Plains of the United States (Ali and Francl, 2003) and in western Canada (Lamari and Bernier, 1989a; Lamari et al., 1998). Tan necrosis and/or chlorosis are typical symptoms of tan spot. These symptoms are mainly induced by toxins produced by different races of $P$. tritici-repentis

Published in Crop Sci. 51:1059-1067 (2011).

doi: 10.2135/cropsci2010.08.0464

Published online 14 Mar. 2011.

(C) Crop Science Society of America | 5585 Guilford Rd., Madison, WI 53711 USA

All rights reserved. No part of this periodical may be reproduced or transmitted in any form or by any means, electronic or mechanical, including photocopying, recording, or any information storage and retrieval system, without permission in writing from the publisher. Permission for printing and for reprinting the material contained herein has been obtained by the publisher. 
(Lamari et al., 2003). Races 1 and 2 of $P$. tritici-repentis produce a host-selective toxin (HST), Ptr ToxA, that induces necrosis symptoms (Ciufetti et al., 1998; Tuori et al., 1995). Ptr ToxA is a well-characterized HST of P. tritici-repentis and the gene that encodes for Ptr ToxA production including the endogenous promoter has been cloned (Ciuffetti et al., 1997; Manning et al., 2003). Tsn1, a single dominant gene that conditions sensitivity to Ptr ToxA on the long arm of chromosome 5B (Faris et al., 1996; Anderson et al., 1999; Liu et al., 2006; Chu et al., 2008c), has recently been cloned (Faris et al., 2010). Race 1 also produces another HST, Ptr ToxC (Effertz et al., 2002). It is a nonionic, polar nonprotein HST toxin that induces chlorosis in sensitive wheat cultivars (Effertz et al., 2002; Singh et al., 2008a). A recessive insensitivity gene of wheat to the toxin (tsc1) was mapped on the short arm of chromosome 1A (Effertz et al., 2002).

Several studies have been conducted to search for potential resistant wheat germplasm to tan spot. Germplasm with a high level of resistance have been identified in tetraploid wheat [Triticum turgidum L. subsp. durum (Desf.) Husn.] (Chu et al., 2008a), synthetic hexaploid wheat (Xu et al., 2004), bread wheat from Brazil (Rees and Platz, 1990), and spring wheat from northern Great Plains (Singh et al., 2006) and the International Maize and Wheat Improvement Center (CIMMYT) (Ali et al., 2008). However, elite winter breeding materials from United States and germplasm from Asia have not been extensively evaluated for resistance to $\tan$ spot. Surveys of tan spot resistance in these germplasm lines may facilitate identification of new adapted breeding materials for commercial production of U.S. winter wheat and new sources of resistance from different origins as parents in breeding programs to enhance genetic diversity of wheat resistance to $P$. tritici-repentis. This study was designed to evaluate U.S. elite winter wheat breeding lines and Asian germplasm from different geographical origins for resistance to race 1 of $P$. tritici-repentis and sensitivity to Ptr ToxA and to identify new sources of resistance to tan spot.

\section{MATERIALS AND METHODS}

\section{Plant Materials}

A total of 380 wheat accessions were evaluated for tan spot resistance, including 212 U.S., 153 Asian, seven South American, and seven European accessions. The U.S. accessions consisted of 187 elite breeding lines and 25 major cultivars released in the hard winter wheat region. Accessions from the United States include those from 2008 U.S. Southern $(n=42)$ and Northern $(n=24)$ Hard Winter Wheat Regional Performance Nurseries, Hard Winter Wheat Regional Germplasm Observation Nursery $(n=37)$, U.S. Uniform Eastern Soft Red Winter Wheat Nursery $(n=33)$, Uniform Southern Soft Red Winter Wheat Nursery $(n=31)$, Oklahoma State University Breeding Nursery (Stillwater, OK) $(n=18)$, and 25 recently released cultivars (Supplemental Table S1). Among them, 116 accessions were hard red winter wheat (HRW), 22 hard white winter wheat
(HWW), and 69 soft red winter wheat (SRW). They were all provided by Dr. Brett Carver from Oklahoma State University, Stillwater, OK. All accessions were purified from a single plant before phenotyping was conducted to eliminate heterogeneity. These U.S. accessions were from nine major hard wheat-growing states (138 hard winter wheat accessions) and 16 major soft wheat-growing states in the United States (71 soft winter wheat accessions). TAM 105 and Karl 92, two hard winter wheat cultivars from the southern Great Plains of the United States, were used as the susceptible and resistant controls, respectively, for disease resistance classification.

\section{Disease Evaluation}

All wheat accessions were evaluated for reaction to race 1 of P. tritici-repentis. Seeds were planted in a rack containing 100 66-mL RLC4 plastic conic tubes (Stuewe and Sons, Corvallis, OR) filled with a mixture of steamed soil:vermiculite (50:50). A cotton ball was placed in the bottom of each tube to prevent soil from leaking out. One seed per accession was planted in each tube. A randomized complete block design was used with 10 replications (Bockus et al., 2007). Four racks (one replication) were planted each day to accommodate all 380 accessions plus checks and all replications were planted in 10 consecutive days.

Plants were grown under light for $12 \mathrm{~h}$ at $25^{\circ} \mathrm{C}$ and darkness for $12 \mathrm{~h}$ at $21^{\circ} \mathrm{C}$ after planting. When plants reached the 4-leaf stage (about 4 wk after seeding), seedlings were sprayed with a spore suspension $\left(\sim 5,000\right.$ spores $\left.\mathrm{mL}^{-1}\right)$ of the isolate AZ-00 (race 1) of P. tritici-repentis. Spores were produced by transferring a small disc of mycelium of the fungus from 1/4-strength potato-dextrose agar to the center of V-8 agar plates $(150 \mathrm{~mL}$ V-8 100\% Vegetable Juice [Campbell Soup Company, Camden, $\mathrm{NJ}$, $3 \mathrm{~g} \mathrm{CaCO}_{3}, 15 \mathrm{~g}$ agar, and $850 \mathrm{~mL}$ water), flattening aerial hyphae with a sterile, bent-glass rod around the perimeter when the colony reached about 4 to $5 \mathrm{~cm}$ in diameter (about $5 \mathrm{~d}$ in the dark at $21-24^{\circ} \mathrm{C}$ ), and incubating for $12 \mathrm{~h}$ in the light at $22^{\circ} \mathrm{C}$ followed by $12 \mathrm{~h}$ dark at $18^{\circ} \mathrm{C}$. To produce suspensions, plates were flooded with distilled water and spores dislodged using a transfer loop. Approximately $35 \mathrm{~mL}$ spore suspension was applied to each rack using a De-Vilbiss atomizer (Micromedics Inc., St. Paul, MN) at $172 \mathrm{kPa}$ (Singh et al., 2008b). Racks were placed in a mist chamber with $100 \%$ relative humidity for $48 \mathrm{~h}$ at 20 to $28^{\circ} \mathrm{C}$ with a $12 \mathrm{~h}$ photoperiod. Plants were returned to the original greenhouse benches $48 \mathrm{~h}$ after inoculation. Seven days after inoculation, the bottom three fully expanded leaves were scored based on the estimated percent leaf area diseased (\%LAD), ranging from 0 to $100 \%$ at $5 \%$ intervals. Both necrosis and chlorosis were scored from three inoculated leaves of each plant and were averaged to obtain an overall \%LAD for the plant.

\section{Ptr ToxA Assay}

After tan spot was scored, approximately $100 \mu \mathrm{L}$ of partially purified Ptr ToxA was infiltrated into the fourth leaf of at least three seedling plants using a Hagborg device (Hagborg, 1970). The boundaries of the infiltration areas were marked with a fine point nontoxic pen right after infiltration. Leaves were evaluated for reaction to the toxin $4 \mathrm{~d}$ after infiltration and were scored as either sensitive $(+, 1)$ or insensitive $(-, 0)$ to toxin. 


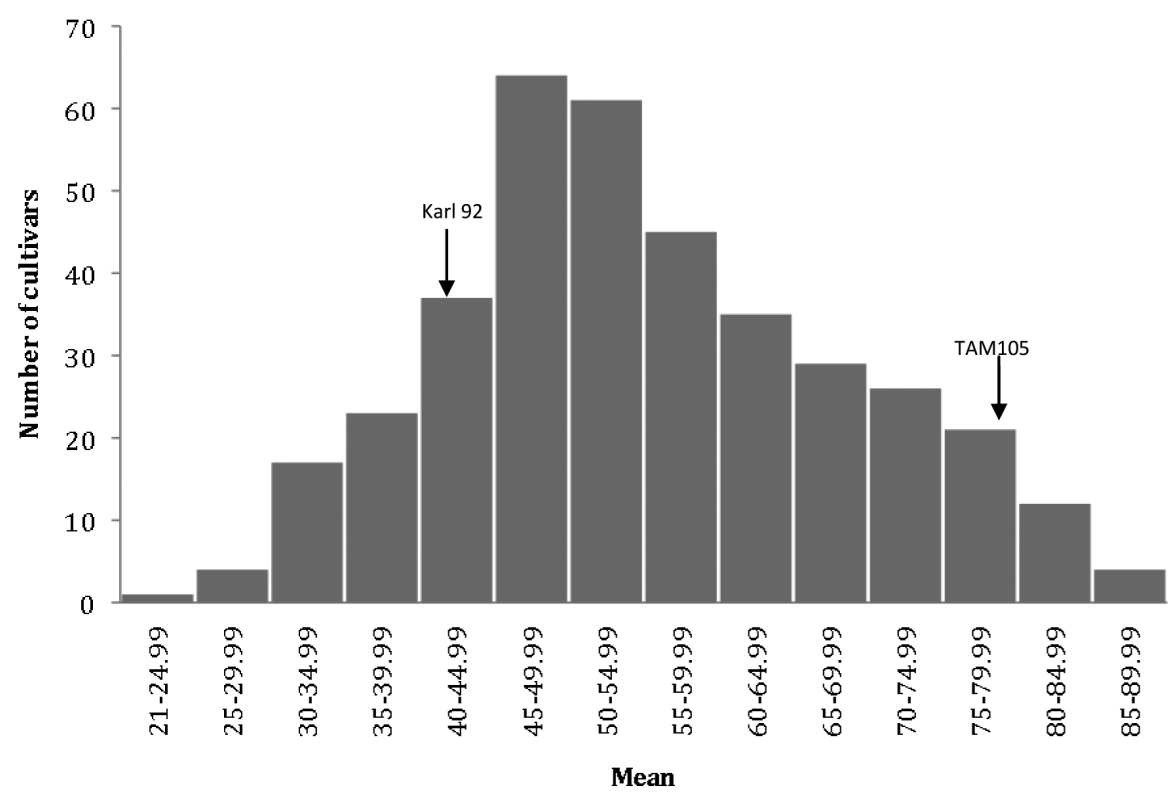

Figure 1. Frequency distribution of leaf area diseased for 380 wheat accessions.

\section{Statistical Analysis}

Statistical analysis was performed using the Statistical Analysis System (SAS Institute, 2003). Analysis of variance (ANOVA) was performed to test the difference in reactions of wheat accessions to $P$. tritici-repentis among accessions. Least significant difference (LSD) was computed and used as a basis for grouping the accessions into different categories. Correlation was analyzed to evaluate the relationship between sensitivity to Ptr ToxA and average reaction to $P$. tritici-repentis.

\section{RESULTS}

\section{Wheat Reactions to Race 1 of Pyrenophora tritici-repentis}

Wheat accessions varied greatly in reactions to race 1 of P. tritici-repentis (Fig. 1). The resistant control Karl 92 had an average \%LAD of $42.9 \%$, ranging from 35.2 to $48.7 \%$, while the susceptible control TAM 105 had an average \%LAD of $79.2 \%$, ranging from 77 to $82.3 \%$. Leaf area diseased ranged from 21.9 to $87.8 \%$ with an average of $55.3 \%$ for all accessions tested (Supplemental Table S1). Frequency distribution of \%LAD in the collection was continuous but skewed toward the resistant control Karl 92 (Fig. 1). To classify tested materials into different resistance categories, all accessions were compared with mean of resistant and susceptible controls and the LSD value. Hence, tested accessions were grouped as highly resistant (\%LAD $\leq 28.5$; better resistance than Karl 92), resistant $(28.5<\%$ LAD $\leq 57.4$; similar to Karl 92), moderately susceptible (57.4 $<\%$ LAD < 64.8; between Karl 92 and TAM 105), and susceptible (\%LAD $\geq 64.8$; similar to TAM 105). The 379 accessions include five highly resistant, 224 resistant, 57 moderately susceptible, and 93 susceptible (Table 1). Thus, $60 \%$ accessions in this study showed similar or better resistance than Karl 92 and less than a quarter of accessions were as susceptible as TAM 105. The highly resistant accessions $(1.3 \%)$ include four accessions from the United States and one from China and the resistant accessions include 112 accessions from the United States, 102 from Asia, four from South America, and six from Europe. Because all materials were chosen without any regard to reactions to tan spot, the materials used in this study represented a random collection in regard to tan spot resistance.

The U.S. accessions used in the study are mainly elite breeding lines or newly released cultivars of different market classes from major U.S. hard and soft winter wheat breeding programs of the Great Plains and eastern and midwestern United States (Table 2). Most of them were resistant to tan spot infection irrespective of market class. In total, 112 out of 212 U.S. accessions were resistant to tan spot. The proportion of resistant accessions to the total number of accessions varied among market classes. A higher percentage of resistant accessions were observed in SRW (71\%) than in HRW (45\%). The four highly resistant U.S. accessions also belong to the SRW class $(\mathrm{La} 01 \star 425$, M03-3616C, KY97C-0519-04-07, and MO040152).

Many resistant accessions from the United States share common resistant parents. Resistant accessions OK06313, India Exp, and KS010957K 4 shared a common parent, Karl 92, in their pedigrees. This suggests that the resistance gene(s) in Karl 92 had a high heritability for resistance to P. tritici-repentis race 1. Resistance of accessions U07-6989, TX04M410211, OK04505, AP05T2413, HV9W02942R, Overley, TX01V5134RC, OK05830, OK04507, KS020304K 3, and OK01420W appeared to be contributed by Jagger because Jagger was one of their parents and showed high resistance to tan spot (Sears et al., 1997).

The majority of Asian accessions used in this study were either Funo-related or landraces (Table 3). Similar to the U.S. 
Table 1. Geographical origin and classification of resistance to Pyrenophora tritici-repentis of 379 wheat accessions.

\begin{tabular}{|c|c|c|c|c|c|c|c|c|c|c|}
\hline \multirow[b]{2}{*}{ Origin } & \multicolumn{5}{|c|}{ No. of accessions ${ }^{\dagger}$} & \multicolumn{5}{|c|}{ No. of ToxA insensitive accessions ${ }^{\ddagger}$} \\
\hline & HR & $\mathbf{R}$ & MS & $\mathrm{S}$ & Total & $\mathrm{HR}$ & $\mathbf{R}$ & MS & $\mathrm{S}$ & Total \\
\hline United States & 4 & 112 & 29 & 67 & 212 & 3 & 69 & 10 & 27 & 109 \\
\hline Asia & 1 & 102 & 28 & 22 & 153 & 1 & 76 & 21 & 10 & 108 \\
\hline China & 1 & 79 & 26 & 16 & 122 & 1 & 59 & 20 & 7 & 87 \\
\hline Japan & 0 & 20 & 2 & 6 & 28 & 0 & 15 & 1 & 3 & 19 \\
\hline Korea & 0 & 3 & 0 & 0 & 3 & 0 & 2 & 0 & 0 & 2 \\
\hline South America & 0 & 4 & 0 & 3 & 7 & 0 & 4 & 1 & 2 & 7 \\
\hline Europe & 0 & 6 & 0 & 1 & 7 & 0 & 5 & 0 & 1 & 6 \\
\hline Total & 5 & 224 & 57 & 93 & 379 & 4 & 154 & 32 & 40 & 230 \\
\hline
\end{tabular}

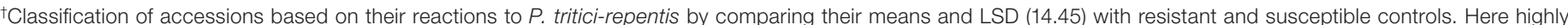

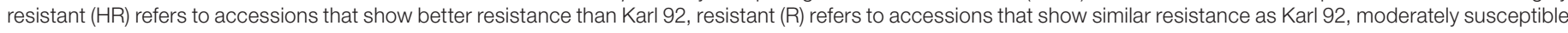

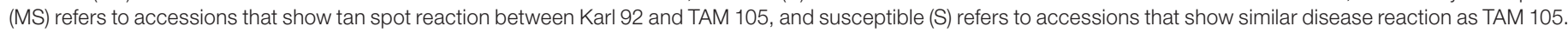

‡No. of accessions insensitive to Ptr ToxA in each resistance class.

Table 2. Reactions of different classes of U.S. wheat accessions to infection of Pyrenophora tritici-repentis and infiltration of Ptr ToxA.

\begin{tabular}{|c|c|c|c|c|c|c|c|c|c|c|}
\hline \multirow[b]{2}{*}{ Market classes } & \multicolumn{5}{|c|}{ No. of accessions ${ }^{\dagger}$} & \multicolumn{5}{|c|}{ No. of accessions ${ }^{\ddagger}$} \\
\hline & $\mathrm{HR}$ & $\mathrm{R}$ & MS & $\mathrm{S}$ & Total & HR & $\mathrm{R}$ & MS & $\mathrm{S}$ & Total \\
\hline Hard red winter & 0 & 52 & 18 & 46 & 116 & 0 & 16 & 2 & 13 & 31 \\
\hline Hard white winter & 0 & 10 & 2 & 10 & 22 & 0 & 4 & 0 & 5 & 9 \\
\hline Soft red winter & 4 & 49 & 7 & 9 & 69 & 3 & 48 & 6 & 8 & 65 \\
\hline Soft white winter & 0 & 1 & 1 & 0 & 2 & 0 & 1 & 1 & 0 & 2 \\
\hline Hard red spring & 0 & 0 & 1 & 2 & 3 & 0 & 0 & 1 & 1 & 2 \\
\hline Total & 4 & 112 & 29 & 67 & 212 & 3 & 69 & 10 & 27 & 109 \\
\hline
\end{tabular}

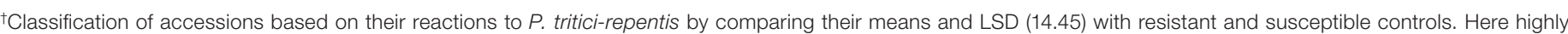

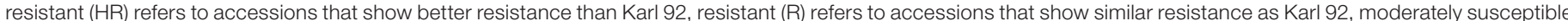

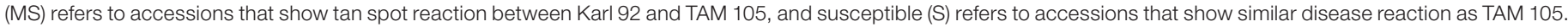
‡No. of accessions insensitive to Ptr ToxA in each tan spot reaction class.

accessions, more resistant Asian accessions (67\%) were also observed than susceptible accessions (14\%). Funo, an Italian variety, was introduced to China in the 1960s and has been widely used as a parent for Chinese wheat improvement. Among 153 Asian accessions, 57 were Funo-related and 31 of them (54\%) were resistant with one (Linnong12) showing better resistance than Karl 92. Funo, which also had a low $\%$ LAD of $43.15 \%$, might be the major contributor to the resistance for these accessions. An even higher rate of accessions $(76 \%)$ was identified to be resistant in landraces than Funo-related accessions in the Asian collection.

\section{Wheat Insensitivity to Ptr ToxA}

TAM 105, the susceptible control, was sensitive to Ptr ToxA, whereas Karl 92 was not. After infiltration with Ptr ToxA, leaves of sensitive accessions showed necrosis on the infiltrated leaf area within 3 to $4 \mathrm{~d}$ after toxin infiltration, but insensitive accessions did not show any symptom. Of the 379 accessions, only 150 showed necrosis after toxin infiltration and the rest were all insensitive to Ptr ToxA, suggesting that most wheat accessions in the collection are insensitive to Ptr ToxA (Table 1). Some accessions with an insensitive reaction to Ptr ToxA also had similar disease levels as the resistant control. Resistant accessions Atlas66, Chinese Spring, Wangshuibai, Chokwang, and Haiyanzhong also showed insensitivity to Ptr ToxA in this study.
In the 230 accessions that were insensitive to $\mathrm{Ptr}$ ToxA, 40 were highly susceptible to tan spot and displayed extensive chlorosis. For example, highly susceptible cultivars Wheaton and Ning7840 were insensitive to Ptr ToxA. After infiltration, necrosis was not observed in the infiltration areas of these accessions. In the U.S. accessions, 109 were insensitive to Ptr ToxA. Interestingly, almost all of SRW wheat (65 out of 69) were insensitive to Ptr ToxA although some of those were moderately susceptible or susceptible to tan spot. Only one quarter of HRW were insensitive (31 out of 116) to Ptr ToxA (Table 2). Of the 153 Asian accessions, about 71\% (108) were insensitive to Ptr ToxA including 59 landraces and 34 Funo-related accessions. A major portion of Asian resistant accessions (75\%) was insensitive to Ptr ToxA (Table 3).

Overall, a weak positive correlation $(r=0.24, p<$ 0.0001 ) was observed between wheat resistance to $P$. tritici-repentis race 1 and insensitivity to Ptr ToxA. Therefore, some resistant accessions were sensitive to Ptr ToxA and susceptible accessions were insensitive to Ptr ToxA. For example, some resistant accessions such as Anxuan2, OK05212, OK06528, and M04-4715 were sensitive to Ptr ToxA whereas susceptible accessions such as Yangmai4, Yunmai27, and OK06210 were insensitive to the toxin. The results implied that virulence determinants other than Ptr ToxA were involved in tan spot disease in wheat. 
Table 3. Reactions of wheat accessions from China, Japan, and Korea to infection of Pyrenophora tritici-repentis and infiltration of Ptr ToxA.

\begin{tabular}{|c|c|c|c|c|c|c|c|c|c|c|}
\hline \multirow[b]{2}{*}{ Source } & \multicolumn{5}{|c|}{ No. of accessions ${ }^{\dagger}$} & \multicolumn{5}{|c|}{ No. of accessions ${ }^{\ddagger}$} \\
\hline & HR & $\mathbf{R}$ & MS & $\mathrm{S}$ & Total & $\mathrm{HR}$ & $\mathbf{R}$ & MS & $\mathrm{S}$ & Total \\
\hline Landrace & 0 & 57 & 10 & 8 & 75 & 0 & 48 & 7 & 4 & 59 \\
\hline Funo background & 1 & 30 & 16 & 10 & 57 & 1 & 16 & 12 & 5 & 34 \\
\hline Unknown & 0 & 13 & 2 & 3 & 18 & 0 & 10 & 2 & 1 & 13 \\
\hline Cultivar & 0 & 2 & 0 & 1 & 3 & 0 & 2 & 0 & 0 & 2 \\
\hline Total & 1 & 102 & 28 & 22 & 153 & 1 & 76 & 21 & 10 & 108 \\
\hline
\end{tabular}

${ }^{\dagger}$ Classification of accessions based on their reactions to $P$. tritici-repentis by comparing their means and LSD (14.45) with resistant and susceptible controls. Here highly resistant (HR) refers to accessions that show better resistance than Karl 92, resistant (R) refers to accessions that show similar resistance as Karl 92, moderately susceptible (MS) refers to accessions that show tan spot reaction between Karl 92 and TAM 105, and susceptible (S) refers to accessions that show similar disease reaction as TAM 105. ‡No. of accessions insensitive to Ptr ToxA in each tan spot reaction class.

\section{DISCUSSION}

\section{Evaluation of Germplasm for Tan Spot Resistance}

Only a few studies have been conducted to evaluate tan spot resistance in hexaploid wheat. Chu et al. (2008a) evaluated 688 accessions of tetraploid wheat for tan spot resistance, and $\mathrm{Xu}$ et al. (2004) reported tan spot resistance in synthetic hexaploid wheat. In bread wheat, several studies have been conducted on evaluation of tan spot resistance in spring wheat (Singh et al., 2006; Ali et al., 2008). However, tan spot resistance has not been well documented in winter wheat, especially elite breeding lines. This is the first report on evaluation of tan spot resistance in a collection of U.S. elite winter wheat breeding materials and Asian germplasm. The results provided an informative report on the status of tan spot resistance in U.S. breeding programs and Asian germplasm and a guideline for breeders to select parents to improve tan spot resistance in U.S. winter wheat. In addition, many resistant lines identified from Asian sources will be valuable for improving genetic diversity of $\tan$ spot resistance in U.S. wheat breeding programs.

To accurately evaluate tan spot resistance, a reliable method for disease evaluation is important. There are two disease scoring methods that have been reported, a 1 to 5 rating scale of lesion type on the third leaf or newest expanded leaf at the time of inoculation (Lamari and Bernier, 1989b, c; Faris and Friesen, 2005; Faris et al., 1997) and another scale of using an average percent leaf area diseased (\%LAD) of the three bottom leaves (Bockus et al., 2007; Sun et al., 2010). Faris et al. (1997) compared the two rating scales and concluded that they both were highly correlated and gave similar accuracy in tan spot rating in wheat leaves. However, the \%LAD of the three bottom leaves provides an evaluation of disease damage due to inoculation. This rating method showed high repeatability among different plants of each accession and a high correlation of 0.88 in a 1 to 5 lesion rating scale (Bockus et al., 2007; Faris et al., 1996).

The frequency distribution of the disease rating in this study was continuous, and a clear cut was not found between resistant and susceptible accessions. To provide more objective resistance classification of the collection, accessions with known resistance and susceptibility were used as controls and added to each replication to minimize disease scoring error. The two controls, Karl 92 and TAM 105, were selected based on more than $10 \mathrm{yr}$ data (De Wolf et al., 2010) and showed consistently large differences in reaction to tan spot (Singh et al., 2008a). Based on the comparison of each entry to the means of controls using the LSD, all accessions were grouped into four classes: highly resistant, resistant, moderately susceptible, and susceptible. Resulted groups should be useful reference for breeders to select parents for further crosses in breeding programs.

\section{Sources for Tan Spot Resistance}

In this study, $60 \%$ of the accessions were in the resistant to highly resistant categories. These accessions should be a useful resource for breeders to develop disease-resistant germplasm or varieties. Most of the wheat accessions from the United States are breeding lines from regional performance nurseries and could be potential new cultivars after further yield testing. The resistance genes or QTL for tan spot resistance in U.S. wheat appeared to be derived from limited sources because many resistant U.S. accessions shared the same sources of resistance. For instance, Karl 92 has been used in breeding programs since its release in 1988 and has a high level of resistance to tan spot (Bockus et al., 2001); Overley and OK06528 can be traced back to resistant parent Heyne (Bockus et al., 2001); HV9W05$881 \mathrm{R}$ and OK05212 have resistant parent Betty in their pedigrees. U.S. lines M04-4715, D04-5012, HV9W05881R, and TX04M410211 all were resistant and have a common parent Mason which might be the principal contributor of resistance to tan spot. Resistant accessions Karl 92 and Jagger were the major contributors of resistance to many U.S. accessions in our collection. Some resistant accessions performed significantly better than their resistant ancestors as reported by Rees and Platz (1990). However, immunity to $P$. tritici-repentis has not been observed in bread wheat, which agrees with Rees and Platz (1990).

Various proportions of tan spot resistant accessions were observed between market classes and materials from different geographic areas. Gurung et al. (2009) reported that 
resistance to tan spot was associated with winter growth habit and believed that winter environments were conducive to the disease. Winter wheat is vulnerable to $P$. tritici-repentis from winter to May (Raymond et al., 1985). As a result, these U.S. lines may have undergone disease pressure at the time they were tested by breeders and then were selected because of their resistance to many diseases including tan spot. However, results from this study cannot support the hypothesis that winter wheat is more resistant than spring wheat because the majority of Asian lines tested were spring wheat and most of them showed a high level of resistance. Gurung et al. (2009) identified resistant spring wheat accessions from South America, Asia, and Europe but not from the United States. In this study, both U.S. winter wheat and Chinese spring wheat showed resistance to race 1 of $P$. tritici-repentis; thus, they can be useful sources of resistance for breeding for tan spot resistance. The use of elite breeding lines as resistant parents in breeding for tan spot resistance can be very effective since they already have other traits that the breeder has selected such as high yield and resistance to other diseases. Some breeding lines can also be used directly as cultivars after further testing because they are already adapted to the correct environment.

Funo, an Italian cultivar, showed highly heritable resistance to tan spot because 54\% of Funo-related Asian accessions were resistant with one as highly resistant. Funo was introduced to China in 1956 (He et al., 2001) and has been heavily used as a parent in many Chinese breeding programs for more than a decade (Bai et al., 2003). Funo's resistance to tan spot may have been acquired from Rieti, an Italian parent, because Rieti was reported to contribute resistance to Mentana (Rees and Platz, 1990). Frontana showed a high level of resistance in this study and was a derivative of Mentana, a relative of Funo. Thus, Funo can be a good source of resistance due to its high heritability and wide adaptation. Its contribution of resistance of Fusarium head blight (FHB) has also been reported (Shen et al., 2003).

Other sources of resistance to tan spot are landraces. In this study, $76 \%$ of the Asian landraces were resistant to tan spot. Some resistance genes from some landraces have not yet been deployed to modern cultivars and can be useful sources for enhancing genetic diversity of tan spot resistance genes (Bonman et al., 2007). Some landraces have been studied (Harlan, 1975) and many showed resistance to Fusarium (Fusarium graminearum) head blight, stem rust (Puccinia graminis), powdery mildew (Blumeria graminis $\mathrm{f} \mathrm{sp}$. tritici), and drought (Bonman et al., 2007; Wei et al., 2005; Reynolds et al., 2006; Bhullar et al., 2009). However, the use of bread wheat landraces for tan spot resistance has not been exploited. Several studies assessed tan spot resistance in tetraploid, synthetic hexaploid, durum, and wild emmer wheat [Triticum turgidum L. subsp. dicoccoides (Körn. ex Asch. \& Graebn.) Thell.] (Morris et al., 2010; Tadesse et al., 2007; Chu et al., 2008a, b, c, 2010; Xu et al., 2004). As an alternative source, resistance from hexaploid landraces should be easier to use to improve resistance of commercial cultivars than that from other wheat relatives. Some landraces may carry genes that are not currently present in elite breeding lines. Marker-assisted backcrossing may facilitate introgressing these genes to a more adapted cultivar to increase genetic diversity of resistance genes.

\section{Pathogenicity Factors Involved in Tan Spot Development}

Our data suggest that host reaction to Ptr ToxA does not exclusively determine the host's reaction to race 1 of $P$. tritici-repentis. A positive but very weak association was observed between Ptr ToxA and resistance to race 1 of $P$. tritici-repentis. This may be due to the fact that race 1 also produces another toxin ( $\mathrm{Ptr}$ ToxC) that produces the chlorosis symptom in the disease syndrome. Also, resistance to tan spot has been reported to be quantitatively inherited (Faris et al., 1997; Faris and Friesen, 2005, Singh et al., 2010) and controlled by multiple genes (Singh et al., 2008a, 2010). Race-nonspecific resistance to tan spot was reported in chromosomes $1 \mathrm{~B}$ and $3 \mathrm{~B}$ of hexaploid wheat (Faris and Friesen, 2005), rather than tsn1, in a wheat population segregating for Ptr ToxA sensitivity. Thus, insensitivity to Ptr ToxA does not necessarily imply resistance to race 1 (Friesen et al., 2003). Another resistance QTL was identified in chromosome 3AS (Effertz et al., 2002). Singh et al. (2010) suggested that the majority of tan spot resistance genes are insensitivity genes to different toxins, but toxin sensitivity genes or QTL may also exist. Thus, resistance to tan spot is complex and may be collectively controlled by several different genetic factors.

Four combinations of toxin-disease reactions were observed among the accessions: Ptr ToxA insensitive-disease resistant (40.6\%), Ptr ToxA sensitive-disease resistant (19.8\%), Ptr ToxA sensitive-disease susceptible (20.6\%), and Ptr ToxA insensitive-disease susceptible (19\%). Among them, Ptr ToxA insensitive-disease resistant is the largest group. In this group, the insensitivity to Ptr ToxA and tan spot resistance of Atlas66, Chinese Spring, Wangshuibai, Chokwang, and Haiyanzhong have also been reported previously (Liu et al., 2006; Sun, 2009), which indicates that the disease and Ptr ToxA response data collected in this study are repeatable. In this group, most insensitive accessions showed a similar level of resistance as the resistant control Karl 92 and they most likely carry the recessive resistance gene tsn1 (Friesen et al., 2003; Lamari and Bernier, 1991). This is a very useful group of germplasm and the resistance gene in some of the elite breeding lines can be quickly deployed into commercial cultivars.

The next group consists of Ptr ToxA sensitive-disease resistant accessions. This group of accessions apparently carries $T s n 1$ that produces sensitivity to Ptr ToxA. For example, Chinese landrace Anxuan21 and U.S. breeding line OK5212 
were sensitive to Ptr ToxA but showed very low \%LAD of $33 \%$. The tan spot resistance in this group may be due to an insensitivity gene to Ptr ToxC, another toxin produced by the race 1 (Effertz et al., 2002). Due to unavailability of stable, purified Ptr ToxC, we were not able to test this hypothesis experimentally. Further investigation of resistance genes in these accessions will shed light on understanding the mechanisms underlining tan spot resistance.

The third group consists of Ptr ToxA sensitive-disease susceptible accessions. Accessions in this group most likely carry Tsn1, a gene that increases sensitivity to Ptr ToxA and therefore susceptibility to race 1 . However, it is also possible that a gene for sensitivity to Ptr ToxC might be present in some accessions because both necrosis and chlorosis were observed on leaves of some accessions. This group included Endurance (80.17 \%LAD) and Scout 66 (81.67 \%LAD). Ptr ToxA was reported to be sufficient for disease development (Ciuffetti et al., 1997) in some wheat genotypes.

The fourth group is toxin insensitive-disease susceptible (19\%). Tan spot in this group was most likely caused by Ptr ToxC. In this group, although necrosis was not observed on the Ptr ToxA infiltration region, the plants were scored susceptible due to excessive chlorosis in the leaves. This group included Wheaton (76.50\%LAD) and Yunmai 27 (87.83 \%LAD). This observation supports the hypothesis that Ptr ToxC was a major factor for disease development in these accessions because Ptr ToxC induces chlorosis (Effertz et al., 2002). This group of accessions might carry $t s n 1$ but not the insensitivity gene for Ptr ToxC.

A previous study showed that Ptr ToxA can only aggravate the damage by the pathogen to the plant but not directly cause the disease in some wheat genotypes; therefore $\operatorname{Ptr} \operatorname{Tox} A$ is a virulence factor rather than a pathogenicity factor (Friesen et al., 2003). This supports the observation that excessive chlorosis was a major symptom of susceptibility and most susceptible accessions showed excessive chlorosis rather than large necrotic lesions in their leaves. Thus, Ptr ToxC may be the major pathoginicity factor in many susceptible accessions. In addition, we may not be able to rule out other factors as virulence determinants of race 1 of $P$. tritici-repentis (Friesen et al., 2002; Andrie et al., 2007; Effertz et al., 2002) besides Ptr ToxA and Ptr ToxC. Chu et al. (2008b) studied tan spot resistance in $T$. dicoccoides and suggested that other genes besides Tsn1/tsn1 might be involved in governing susceptibility or resistance to tan spot.

\section{Supplemental Information Available}

Supplemental material is available free of charge at http:// www.crops.org/publications/cs.

Supplemental Table 1. Seedling reactions of different wheat accessions to Pyrenophora tritici-repentis and to Ptr ToxA.

\section{Acknowledgment}

This project was supported by the National Research Initiative Competitive Grants CAP project 2011-68002-30029 from the USDA National Institute of Food and Agriculture. All U.S. materials for the study were provided by Dr. Brett Carver from Oklahoma State University, Stillwater, OK. Mention of trade names or commercial products in this article is solely for the purpose of providing specific information and does not imply recommendation or endorsement by the U.S. Department of Agriculture. Contribution No. 11-041-J from the Kansas Agricultural Experiment Station, Manhattan, KS.

\section{References}

Ali, S., and L.J. Francl. 2003. Population race structure of Pyrenophora tritici-repentis prevalent on wheat and noncereal grasses in the Great Plains. Plant Dis. 87:418-422.

Ali, S., P.K. Singh, M.P. McMullen, M. Mergoum, and T.B. Adhikari. 2008. Resistance to multiple leaf spotting diseases in wheat germplasm. Euphytica 159:167-179.

Anderson, J.A., R.J. Effertz, J.D. Faris, L.J. Francl, S.W. Meinhardt, and B.S. Gill. 1999. Genetic analysis of sensitivity to Pyrenophora tritici-repentis necrosis-inducing toxin in durum and common wheat. Phytopathology 89:293-297.

Andrie, R.M., C.L. Schoch, R. Hedges, J.W. Spatafora, and L.M. Ciuffetti. 2007. Homologs of ToxB, a host selective toxin gene from Pyrenophora tritici-repentis, are present in the genome of sister-species Pyrenophora bromi and other members of the Ascomyta. Fungal Genet. Biol. 45:363-377.

Bai, G.H., P.G. Guo, and F.L. Kolb. 2003. Genetic relationships among head blight resistant cultivars of wheat assessed on the basis of molecular markers. Crop Sci. 43:498-507.

Bhullar, N.K., K. Street, M. Mackay, N. Yahiaoui, and B. Keller. 2009. Unlocking wheat genetic resources for molecular identification of previously undescribed functional alleles at the Pms resistance locus. Proc. Natl. Acad. Sci. USA 106:9519-9524.

Bockus, W.W., J.A. Appel, R.L. Bowden, A.K. Fritz, B.S. Gill, T.J. Martin, R.G. Sears, D.L. Seifers, G.L. Brown-Guedira, and M.G. Eversmeyer. 2001. Success stories: Breeding for wheat disease resistance in Kansas. Plant Dis. 85:453-461.

Bockus, W.W., Z. Su, K.A. Garrett, B.S. Gill, J.P. Stack, A.K. Fritz, K.L. Roozeboom, and T.J. Martin. 2007. Number of experiments needed to determine wheat disease phenotypes for four wheat diseases. Plant Dis. 91:103-108.

Bonman, J.M., H.E. Bockman, Y. Jin, R.J. Hijmans, and A.I. Gironella. 2007. Geographic distribution of stem rust resistance in wheat landraces. Crop Sci. 47:1955-1963.

Chu, C.G., S. Chao, T.L. Friesen, J.D. Faris, S. Zhong, and S.S. Xu. 2010. Identification of novel tan spot resistance QTLs using an SSR-based linkage map of tetraploid wheat. Mol. Breed. 25:327-338.

Chu, C.G., T.L. Friesen, J.D. Faris, and S.S. Xu. 2008a. Evaluation of seedling resistance to tan spot and Stagnosphora nodorum blotch in tetraploid wheat. Crop Sci. 48:1107-1116.

Chu, C.G., T.L. Friesen, S.S. Xu, and J.D. Faris. 2008c. Identification of novel tan spot resistance loci beyond the known host-selective toxin insensitivity genes in wheat. Theor. Appl. Genet. 117:873-881.

Chu, C.G., S.S. Xu, J.D. Faris, E. Nevo, and T.L. Friesen. 2008b. Seedling resistance to tan spot and Stagnospora nodorum leaf blotch in wild emmer wheat (Triticum dicoccoides). Plant Dis. 
92:1229-1236.

Ciufetti, L.M., L.J. Francl, G.M. Ballance, W.W. Bockus, L. Lamari, S.W. Meinhardt, and J.B. Rasmussen. 1998. Standardization of toxin nomenclature in the Pyrenophora triticirepentis/wheat interaction. Can. J. Plant Pathol. 20:421-424.

Ciuffetti, L.M., R.P. Tuori, and J.M. Gaventa. 1997. A single gene encodes a selective toxin causal to the development of tan spot of wheat. Plant Cell 9:135-144.

De Wolf, E.E., W.W. Bockus, and J.R. Whitworth. 2010. Wheat variety disease and insect ratings 2010. Publ. MF-991. Kansas State Univ. Agric. Stn. Coop. Ext. Serv., Manhattan, KS.

Effertz, R.J., S.W. Meinhardt, J.A. Anderson, J.G. Jordahl, and L.J. Francl. 2002. Identification of a chlorosis-inducing toxin from Pyrenophora tritici-repentis and the chromosomal location of an insensitivity locus in wheat. Phytopathology 92:527-533.

Faris, J.D., J.A. Anderson, L.J. Francl, and J.G. Jordahl. 1996. Chromosomal location of a gene conditioning insensitivity in wheat to a necrosis-inducing culture filtrate from Pyrenophora tritici-repentis. Phytopathology 86:459-463.

Faris, J.D., J.A. Anderson, L.J. Francl, and J.G. Jordahl. 1997. RFLP mapping of resistance to chlorosis induction by Pyrenophora tritici-repentis in wheat. Theor. Appl. Genet. 94:98-103.

Faris, J.D., and T.L. Friesen. 2005. Identification of quantitative trait loci for race nonspecific resistance to tan spot in wheat. Theor. Appl. Genet. 111:386-392.

Faris, J.D., Z. Zhang, H. Lu, S. Lu, L. Reddy, S. Cloutier, J.P. Fellers, S.W. Meinhardt, J.B. Rasmussen, S.S. Xu, R.P. Oliver, K.J. Simons, and T.L. Friesen. 2010. A unique wheat disease resistance-like gene governs effector-triggered susceptibility to nectotrophic pathogens. Proc. Natl. Acad. Sci. USA 107:13544-13549.

Friesen, T.L., S. Ali, S. Kianian, L.J. Francl, and J.B. Rasmussen. 2003. Role of host sensitivity to Ptr ToxA in development of tan spot of wheat. Phytopathology 93:397-401.

Friesen, T.L., S. Ali, C.Y. Kwon, L.J. Franc, and S.W. Meinhardt. 2002. Reaction of Ptr ToxA-insensitive wheat mutants to Pyrenophora tritici-repentis race 1. Phytopathology 92:38-42.

Gurung, S., J.M. Bonman, S. Ali, J. Patel, M. Myrfield, M. Mergoum, P.K. Singh, and T.B. Adhikari. 2009. New and diverse sources of multiple disease resistance in wheat. Crop Sci. 49:1655-1666.

Hagborg, W.A.F. 1970. A device for injecting solutions and suspensions into thin leaves of plants. Can. J. Bot. 48:1135-1136.

Harlan, J.R. 1975. Our vanishing genetic resources. Science 188:618-621.

He, Z.H., S. Rajaram, Z.Y. Xin, and G.Z. Huang (ed.) 2001. A history of wheat breeding in China. CIMMYT, Mexico, D.F., Mexico.

Lamari, L., and C.C. Bernier. 1989a. Virulence of isolates of Pyrenophora tritici-repentis on 11 wheat cultivars and cytology of the differential host reactions. Can. J. Plant Pathol. 11:284-290.

Lamari, L., and C.C. Bernier. 1989b. Evaluation of wheat lines and cultivars to tan spot [Pyrenophora tritici-repentis] based on lesion type. Can. J. Plant Pathol. 11:49-56.

Lamari, L., and C.C. Bernier. 1989c. Toxin of Pyrenphora triticirepentis: Host-specificity, significance in disease, and inheritance of host reaction. Phytopathology 79:740-744.

Lamari, L., and C.C. Bernier. 1991. Genetics of tan necrosis and extensive chlorosis in tan spot of wheat caused by Pyrenophora tritici-repentis. Phytopathology 81:1092-1095.

Lamari, L., J. Gilbert, and A. Tekauz. 1998. Race differentiation in Pyrenphora tritici-repentis and survey of physiologic variation in western Canada. Can. J. Plant Pathol. 20:396-400.

Lamari, L., B.D. McCallum, and R.M. DePauw. 2005. Forensic pathology of Canadian bread wheat: The cause of tan spot. Phytopathology 95:144-152.

Lamari, L., S.E. Strlkov, A. Yahyaoui, J. Orabi, and R.B. Smith. 2003. The identification of two new races of Pyrenophora tritici-repentis from the host center of diversity confirms a oneto-one relationship in tan spot of wheat. Phytopathology 93:391-396.

Liu, Z., T.L. Friesen, H. Ling, S.W. Meinhardt, R.R. Oliver, J.B. Rasmussen, and J.D. Faris. 2006. The Tsn1-ToxA interaction in the wheat-Stagnosphora nodorum pathosystem parallels that of the wheat-tan spot system. Genome 49:1265-1273.

Manning, V.A., R.M. Andrie, A.F. Trippe, and L.M. Ciuffetti. 2003. Ptr ToxA requires multiple motifs for complete activity. Mol. Plant Microbe Interact. 17:491-501.

Morris, J.F., B.F. Carver, R.M. Hunger, and A.R. Klatt. 2010. Greenhouse assessment of seedling reaction to tan spot in synthetic hexaploid wheat. Crop Sci. 50:952-959.

Murray, G.M., and J.P. Brenan. 2009. Estimating disease losses to the Australian wheat industry. Australas. Plant Pathol. 38:558-570.

Perello, A., V. Moreno, M.R. Simon, and M. Sisterna. 2003. Tan spot of wheat infection at different stages of crop development and inoculums type. Crop Prot. 22:157-169.

Raymond, P.J., W.W. Bockus, and B.L. Norman. 1985. Tan spot of winter wheat: Procedures to determine host response. Phytopathology 75:686-690.

Rees, R.G., and G.J. Platz. 1983. Effects of yellow spot on wheat: Comparison of epidemics at different stages of crop development. Aust. J. Agric. Res. 34:39-46.

Rees, R.G., and G.J. Platz. 1990. Sources of resistance to Pyrenophora tritici-repentis in bread wheat. Euphytica 45:59-69.

Reynolds, M., F. Dreccer, and R. Trethowan. 2006. Droughtadaptive traits derived from wheat wild relatives and landraces. J. Exp. Bot. 58:177-186.

Riede, C.R., L.J. Franc, J.A. Anderson, J.G. Jordahl, and S.W. Meinhardt. 1996. Additional source of resistance to tan spot of wheat. Crop Sci. 36:771-777.

SAS Institute. 2003. Version 9.1. SAS Institute Inc., Cary, NC.

Sears, R.G., J.M. Moffatt, T.J. Martin, T.S. Cox, R.K. Bequette, S.P. Curran, O.K. Chung, W.F. Heer, J.H. Long, and M.D. Witt. 1997. Registration of 'Jagger' wheat. Crop Sci. 37:1010.

Shen, X., M. Zhou, W. Lu, and H. Ohm. 2003. Detection of Fusarium head blight resistance QTL in a wheat population using bulked segregant analysis. Theor. Appl. Genet. 106:1041-1047.

Singh, P.K., M. Mergoum, S. Ali, T.B. Adhikari, E.M. Elias, J.A. Anderson, K.D. Glover, and W.A. Berzonsky. 2006. Evaluation of elite wheat germplasm for resistance to tan spot. Plant Dis. 90(10):1320-1325.

Singh, P.K., M. Mergoum, S. Ali, T.B. Adhikari, and G.R. Hughes. 2008b. Genetic analysis of resistance to Pyrenophora tritici-repentis races 1 and 5 in tetraploid and hexaploid wheat. Phytopathology 98:702-708.

Singh, P.K., R.P. Singh, E. Duveiller, M. Mergoum, T.B. Adhikari, and E.M. Elias. 2010. Genetics of wheat-Pyrenophora tritici-repentis interactions. Euphytica 171:1-13.

Singh, S., W.W. Bockus, I. Sharma, and R.L. Bowden. 2008a. A novel source of resistance in wheat to Pyrenophora tritici-repentis race 1. Plant Dis. 92:91-95.

Sun, X.C. 2009. Genetic characterization of wheat genes resistance 
to tan spot and leaf rust. M.S. thesis. Kansas State University, Manhattan, KS.

Sun, X.C., W. Bockus, and G.H. Bai. 2010. Quantitative trait loci for resistance to Pyrenophora tritici-repentis race 1 in a Chinese wheat. Phytopathology 100:468-473.

Tadesse, W., M. Schmolke, S.L.K. Hsam, V. Mohler, G. Wenzel, and F.J. Zeller. 2007. Molecular mapping of resistance genes to tan spot [Pyrenophora tritici-repentis race 1] in synthetic wheat lines. Theor. Appl. Genet. 114:855-862.

Tekauz, A., E. Muller, M. Stulzer, and D. Schultz. 2004. Leaf spot diseases of winter wheat in Manitoba in 2003. Can. Plant Dis. Surv. 83:73-74.
Tuori, R.P., T.J. Wolpert, and L.M. Ciuffetti. 1995. Purification and immunological characterization of toxic components from cultures of Pyrenophora tritici-repentis. Mol. Plant Microbe Interact. 8:41-48.

Wei, Y.M., Y.C. Huo, Z.H. Yan, W. Wu, Z.Q. Zhang, D.C. Liu, and Y.L. Zheng. 2005. Microsatellite DNA polymorphism divergence in Chinese wheat (Triticum aestivum L.) landraces highly resistant to Fusarium head blight. J. Appl. Genet. 46(1):3-9.

Xu, S.S., T.L. Friesen, and A. Mujeeb-Kazi. 2004. Seedling resistance to tan spot and Stagnosphora nodorum blotch in synthetic hexaploid wheats. Crop Sci. 44:2238-2245. 